\title{
FAILURE OF DAM CONCRETE SUBJECTED TO SEISMIC LOADING CONDITIONS
}

\author{
E. BRUHWILER and F. H. WITTMANN \\ Swiss Federal Institute of Technology, Laboratory for Building Materials, Lausanne, Switzerland
}

\begin{abstract}
Abotract-The numerical simulation of concrete dams subjected to earthquake loading requires realistic material laws which take into account seismic loading conditions. Dynamic tests were performed in order to examine the effect of initially applied compressive loading on material properties of a dam concrete at high tensile deformation rates. The test results show that no important fracture property is reduced at high deformation rates; the tensile strength and the specific fracture energy $G_{F}$ show a high rate sensitivity. However, dynamic compressive pre-loading leads to a reduction of the fracture properties at both quasi-static and high deformation rates.
\end{abstract}

\section{INTRODUCTION}

THE NUMERICAL simulation of concrete dams subjected to earthquakes includes not only the structure and its material properties, but also the effect of soil-structure and reservoir-structure interaction. In view of this very complex analysis, simple but realistic material laws which take into consideration seismic loading conditions, are required for the structural analysis.

Seismic loading is characterized by mainly horizontal motions. Irregular vibrations of a frequency of $1-15 \mathrm{~Hz}$ and ground acceleration of at most $0.2-0.5 \mathrm{~g}$ occur. The structure and hence the material is exposed to alternating excitations at high loading rates, i.e. strain rates $\dot{\epsilon}$ of $10^{-4}<\dot{\epsilon}<1$ per s. During an earthquake, several parts of the dam may suffer tensile loading with subsequent crack formation. Thus, the safety of these large unreinforced concrete structures when subjected to earthquakes is often controlled by the tensile behaviour and cracking of concrete. Crack formation in dams and the consequences may be analysed by means of fracture mechanics methods.

In the last few years, important efforts have been undertaken in order to study, both theoretically and experimentally the behaviour of concrete under high loading rates[1]. However, these studies have not examined the material properties at high loading rates following dynamic compressive loading. Before concrete is loaded, microcracks already in both the cement matrix and along aggregate inclusions, may grow under compressive loading and consequently reduce the material properties in tension. Therefore, for the current investigation dynamic tests were carried out in order to study the effect of initially applied compressive loading on the fracture properties of dam concrete at high deformation rates[2].

\section{FRACTURE PROPERTIES OF DAM CONCRETE AT QUASI-STATIC LOADING RATES}

Concrete used for the construction of dams and common concrete differ mainly in the grain size and in the nature of the aggregates. Because of their origin in the neighbourhood of the dam, the crushed aggregates of dam concrete may have poorer strength than the rolled gravel used for common concrete, and, consequently, strength of dam concrete may be lower. Therefore, an "extrapolation" from common concrete to dam concrete cannot be made directly.

In order to determine the specific fracture energy $G_{\mathrm{F}}$ of dam concrete, wedge splitting tests were performed. The principle of this test method[3] consists in splitting a notched specimen by means of wedges pressed between rollers placed on the top of the specimen. Wedge splitting specimens have a large fracture area compared to the specimen weight. Drilled cores can easily be used as specimens. Therefore, this method is suitable for testing dam concrete. Cylindrical wedge splitting specimens drilled from three existing dams were tested[2], and bilinear strain-softening relations were evaluated using a numerical method[4]. 
$G_{\mathrm{F}}$-values of 175,235 and $257 \mathrm{~N} / \mathrm{m}$ were obtained for these three different dam concretes. This means that the $G_{\mathrm{F}}$-value of dam concrete is two to three times larger than the $G_{\mathrm{F}}$ of common concrete. Since the tensile strength and the modulus of elasticity of dam concrete are smaller than those obtained for common concrete, the characteristic length $l_{\mathrm{ch}}=E \cdot G_{\mathrm{F}} / f_{\mathrm{t}}^{2}$ of dam concrete is up to 10 times larger than for common concrete; $l_{\mathrm{ch}}$-values of 1100,1300 and $1700 \mathrm{~mm}$ were obtained for the three dam concretes tested. The evaluated strain softening diagrams reveal very large crack width values; maximum crack width of $0.40 \mathrm{~mm}$ was evaluated for one dam concrete. It can be concluded that nonlinear models like fracture process zone models should be applied even for dam structures like arch dams, buttress dams and the crest part of gravity dams[2].

It is interesting to note that the fracture surface of dam concrete specimens was characterized by mainly aggregate failures. This may be explained by the relatively low strength of the aggregates used for the construction of dams. However, it seems that a lot of energy is need to break aggregates like gneiss which has a laminar texture. These findings indicate that the high $G_{\mathrm{F}}$-value of dam concrete is rather the result of the nature and material properties of the aggregates than of the aggregate size.

\section{DYNAMIC TESTS}

The complete tensile stress-strain diagram of concrete, which can be subdivided into two portions, is investigated by means of two types of tests:

- uniaxial tests to study the ascending branch of the stress-strain curve; and

-wedge splitting tests to examine the decending branch with strain-softening.

\subsection{Test specimens}

In both series, cylindrical specimens having a diameter of $200 \mathrm{~mm}$ were tested. These concrete cylinders were drilled from blocks which have been poured on the structural site of a dam in the Swiss Alps. This dam concrete with a cement content of $250 \mathrm{~kg} / \mathrm{m}^{3}$ and a water-cement ratio of 0.5 , was made of crushed aggregates with a maximum grain size of $80 \mathrm{~mm}$. These aggregates consist of metamorphic rocks (granite, gneiss, mica shist, quartz) and limestone.

The strength of the dam concrete was determined on cylinders with a diameter of $200 \mathrm{~mm}$ and a height of $600 \mathrm{~mm}$. The following values were obtained for the concrete at an age of two years: compressive strength $f_{\mathrm{cc}}=39 \mathrm{~N} / \mathrm{mm}^{2}$, tensile strength $f_{\mathrm{t}}=2.4 \mathrm{~N} / \mathrm{mm}^{2}$, modulus of elasticity $E=36400 \mathrm{~N} / \mathrm{mm}^{2}$ (both in tension and in compression).

The aim of the dynamic tests is to seize the effect of strain rate and compressive preloading on the fracture properties; the absolute test values are only of secondary importance. Therefore, test results are normalized with respect to the quasi-static properties of the unpreloaded dam concrete. Under the assumption that the observed effects of rate and preloading are also valid for other dam concretes, this normalized presentation enables a more general use of the test results (Section 4).

\subsection{Tensile tests}

A detailed description of these experiments is given in[5]. Uniaxial tests on cylindrical dam concrete specimens (Fig. 1a) were controlled by means of deformation (strain). In order to examine the effect of preceding dynamic compressive loading on the tensile behaviour at high strain rates, the following "loading histories", representing typical seismic loading conditions, were chosen (Fig. 1b):

A. Pure tension: tensile loading to failure at different strain rates.

B. Tension after simple compression: compressive loading to a certain strain level and subsequent tensile loading to failure at different strain rates.

C. Tension after several cycles of compression: repeated compressive loading at constant amplitude and a certain mean strain level with subsequent tensile loading to failure at different strain rates. 
(a)

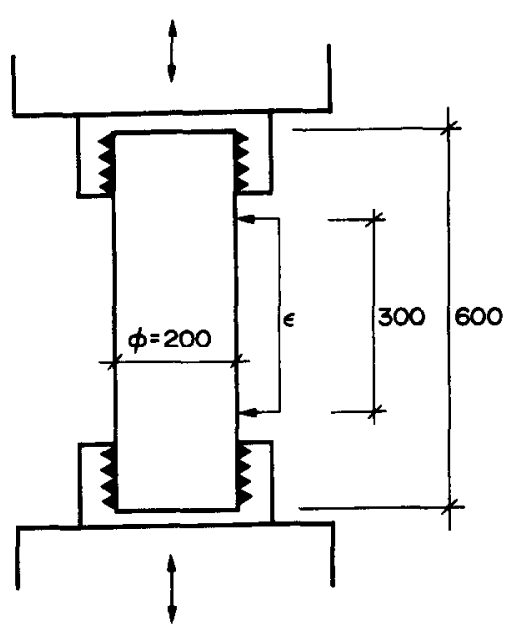

(b)

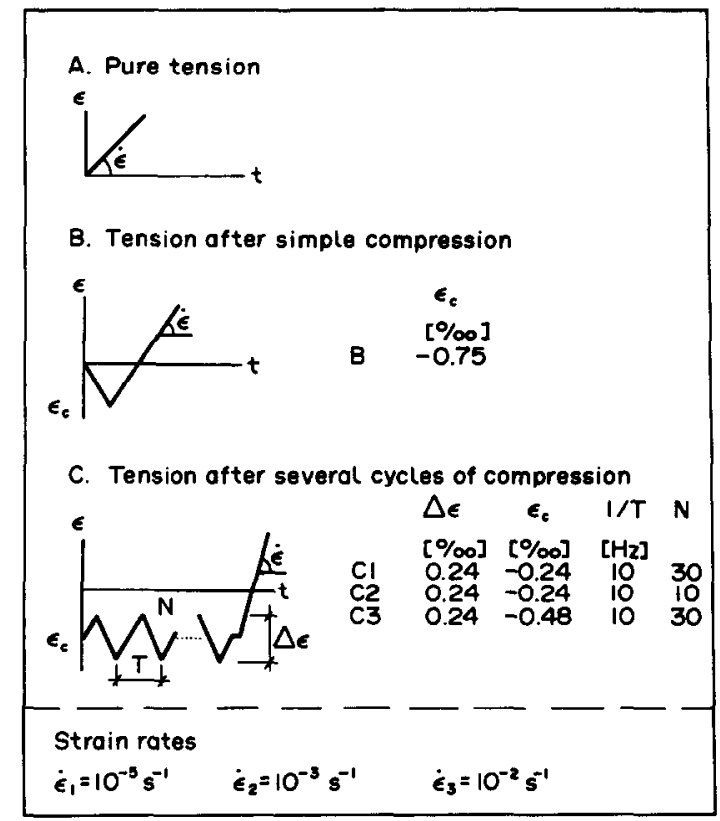

Fig. 1. Tensile tests. (a) Dimensions (in mm) of the specimens. (b) Schematic presentation of the "loading histories" and the chosen parameters.

The tensile strain rate $\dot{\epsilon}$ of the final tensile loading was varied between $10^{-5}$ and $10^{-2}$ per $\mathrm{s}$. The strain rate of $\dot{\epsilon}=10^{-5}$ per $s$ was considered to be the quasi-static strain rate. In a deformation controlled tensile test, an overall load-deformation-curve with a descending branch can generally be recorded. This complete curve was measured at low strain rates. However, at high strain rates, the tests could no longer be controlled and subsequently the specimens failed in a violent manner.

For each series, a power law relating the tensile strength $f_{\mathrm{t}}$ and the modulus of elasticity $E$ to the tensile strain rate has been determined by means of a least squares fit. With the help of a stochastic approach Mihashi and Wittmann[6] have predicted a power law for the rate-sensitivity of strength. The evaluated power functions are shown in Fig. 2. All test results were related to the quasi-static tests without preloading (series A). In order to compare the "loading histories", the "intensity" of the preceding compressive loading was quantified in two ways [5]: first, the energy dissipated during compressive preloading was determined from the area under the compressive stress-strain diagram (including the energy dissipated during the load-cycles). "Loading history" C3 showed by far the highest energy dissipation. The compressive strain level is another value
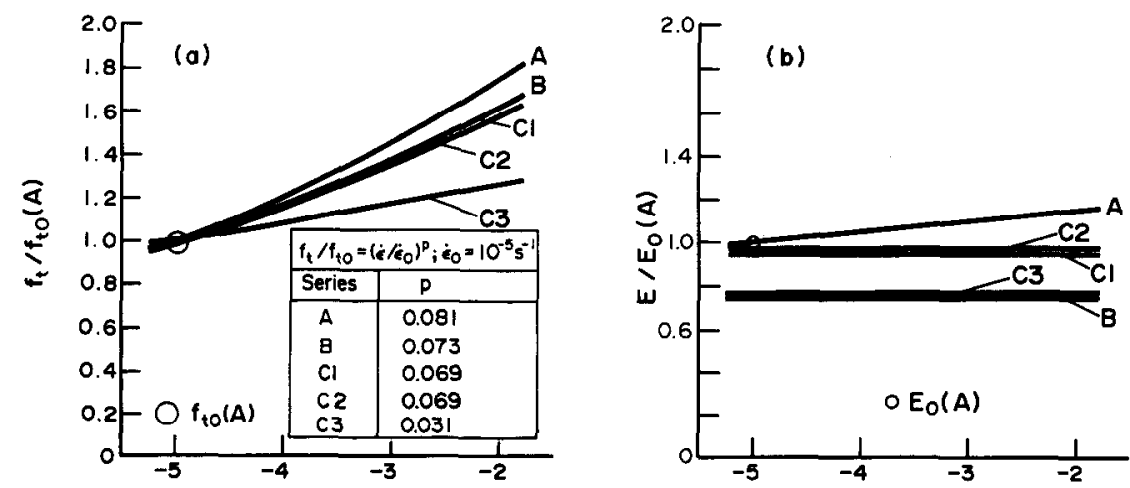

$\log \dot{\epsilon}\left(s^{-1}\right)$

Fig. 2. Effect of compressive preloading and high strain rates on: (a) the tensile strength; and (b) the modulus of elasticity. 
which allows us to quantity the "intensity" of the compressive preloading. The highest compressive strain level was applied in series B.

The results of pure tension tests (series A) are compared to those of tensile tests after initially applied compressive loading (series: $\mathrm{B}, \mathrm{Cl}-\mathrm{C} 3$ ). The main findings are:

-Irrespective of preloading, higher strain rates yield higher tensile strength values (Fig. 2a). However, this rate sensitivity is reduced with increasing intensity of compressive preloading. At quasi-static strain rates, the tensile strength is the same for both preloaded and unpreloaded concrete. This means that only the rate sensitivity is reduced due to compressive preloading.

-The exponent $p=0.081$ in the power law for the tensile strength of the tested dam concrete is larger than for common concrete, for which $p$-values of about 0.055 are found[1]. Rate sensitivity depends on the concrete quality; i.e. the lower strength concrete (dam concrete) is more rate sensitive than the higher strength concrete (common concrete).

- The modulus of elasticity of unpreloaded dam concrete increases with higher strain rates (Fig. 2b), whereas the modulus of elasticity of preloaded concrete is independent of strain rates. The higher the strain level of the compressive preloading, the stronger the reduction of the modulus of elasticity with respect to unpreloaded concrete.

- No rate sensitivity could be observed for the failure strain; i.e. tensile strain at maximum tensile stress. The failure strain increases with growing intensity of compressive preloading (and thus decreasing modulus of elasticity), and the energy stored in the specimen at maximum stress is the same irrespective of the "loading history".

-Examination of fracture surfaces of unpreloaded concrete revealed an increase of the total area of broken aggregates with higher rates. Under the influence of compressive preloading, the amount of aggregate failure was the same for all strain rates tested.

\subsection{Wedge splitting tests}

The wedge splitting tests on the same dam concrete as used for the tensile tests can be subdivided into two series:

-The influence of COD-rate on the specific fracture energy $G_{\mathrm{F}}$ and the strain softening diagram has been studied using cylindrical specimens shown in Fig. 3(a). The main drawback of this specimen shape is that it needs a longitudinal reinforcement in order to prevent shear failure of the cantilevers. For the highest COD-rate of about 10,000 times the quasi-static rate, a strain rate $\dot{\epsilon}$ of $5 \times 10^{-2}$ per $s$ at the notch tip was found by a rough estimation. (It should be noted that this strain rate descreases with propagating fracture zone.)

- Fragments of cylinders previously tested and preloaded in the tensile test series, were used to investigate the effect of compressive preloading on $G_{F}$ and the strain-softening diagram at quasi-static COD-rates (Fig. 3b). As in the uniaxial tensile test, the fracture surface of these wedge splitting specimens is perpendicular to the axis of the cyclinder.

(a)

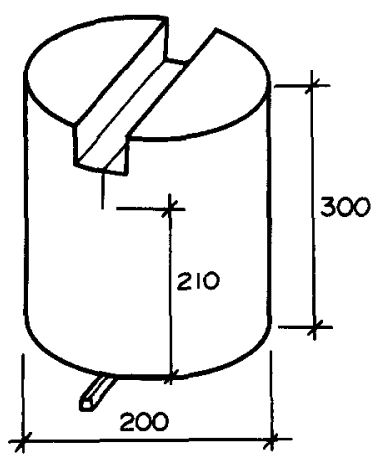

(b)

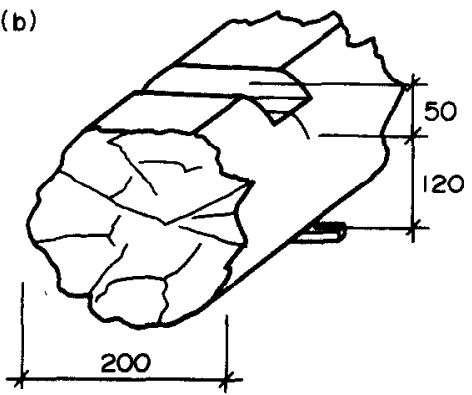

Fig. 3. Wedge splitting tests: Dimensions (in $\mathrm{mm}$ ) of the specimens used in order to investigate the effect of: (a) crack opening displacement rate on $G_{F}$; and (b) compressive preloading on $G_{\mathrm{F}}$ at quasi-static COD-rate. 

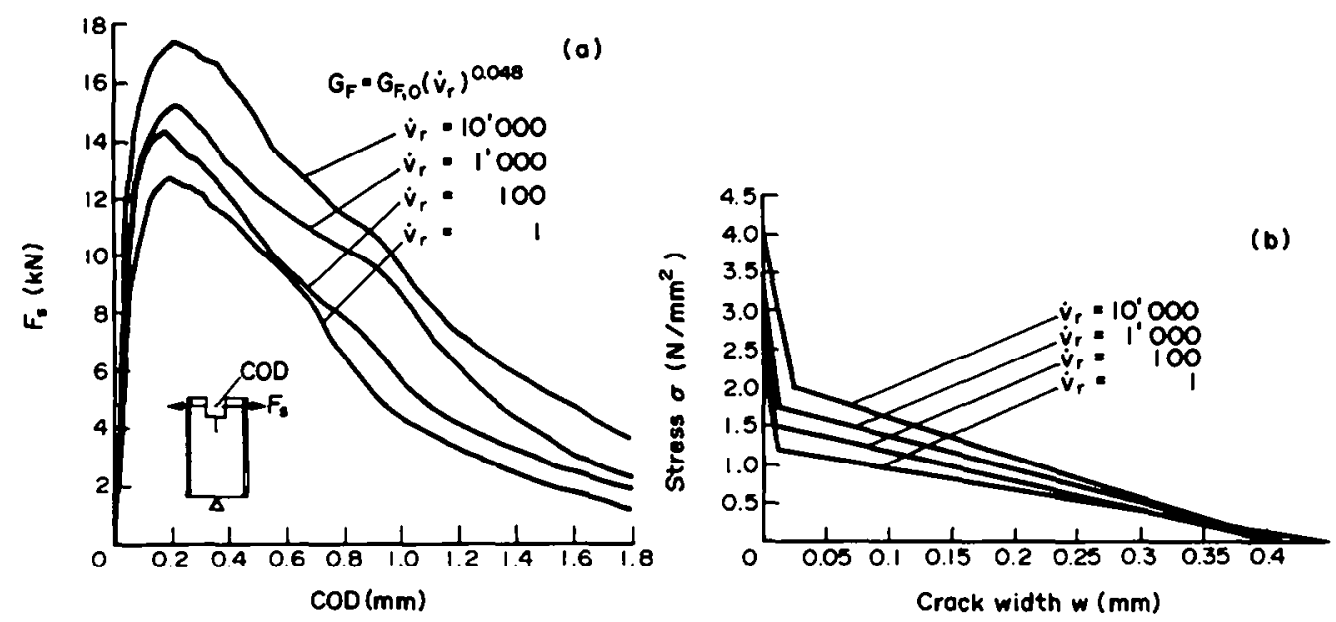

Fig. 4. (a) Splitting force-crack opening displacement-mean curves at four different relative COD-rates $\left(\dot{v}_{\mathrm{r}}=1\right.$ : quasi-static COD-rate). (b) Bilinear strain-softening diagrams.

Remark. The specimen dimensions are relatively small compared to the aggregate size, i.e. smaller than three times the maximum grain size. Nevertheless the test results showed relatively low scatter. This may be explained by the observed fracture behaviour of dam concrete: The crack does not travel around the aggregates; it goes straight through the aggregates.

The splitting force $F_{\mathrm{s}}-\mathrm{COD}$-curves from both tests series are given in Figs $4(\mathrm{a})$ and $5(\mathrm{a})$. The relation between the COD-rate and $G_{F}$ is also expressed by a power law. The numerically evaluated, bilinear strain softening relations are presented in Figs $4(\mathrm{~b})$ and $5(\mathrm{~b})$. The main results are listed below.

Effect of COD-rate.

-The splitting force $F_{\mathrm{s}}$-COD-curves at different COD-rates have similar shapes (Fig. $4 \mathrm{a}$ ). Higher COD-rates yield higher $G_{\mathrm{F}}$-values and higher maximum splitting forces values. The $G_{\mathrm{F}}$-value at a COD-rate of $10^{4}$ times the quasi-static rate is some $80 \%$ higher than the quasi-static $G_{\mathrm{F}}$-value.

- The bilinear strain softening diagrams show that the values of the maximum crack width are the same irrespective of the COD-rate. The rate sensitivity of the strain softening diagram and thus of the $G_{\mathrm{F}}$-value can be attributed to the rate sensitivity of the tensile strength (Fig. $4 \mathrm{~b}$ ).

\section{Effect of compressive preloading.}

- The specific fracture energy $G_{\mathrm{F}}$ at quasi-static deformation rates decreases with increasing intensity of initially applied compressive loading.

- The maximum splitting force is not affected by compressive preloads. (This result coincides with findings from the uniaxial tests.) The slope of the descending branch of the $F_{s}$-COD-curve becomes steeper with increasing intensity of compressive preloading (Fig. Sa).

-With increasing intensity of compressive preloading, the bilinear strain softening diagrams show smaller maximum crack width values (Fig. 5b).

\section{APPLICATION OF THE TEST RESULTS}

With the results of our dynamic tests on dam concrete under seismic loading conditions, material models describing tensile behaviour (including fracture) under seismic loading conditions may be developed. The test results can be summarized as follows:

-No important fracture mechanics property is reduced with higher deformation rate. The rate-sensitivity of certain properties is small and may be neglected in order to simplify matters.

-Dynamic compressive loading leads to material damage, which results in a decrease of the values of the fracture properties. With increasing "intensity" of initially applied compressive loading, this reduction is more pronounced. 

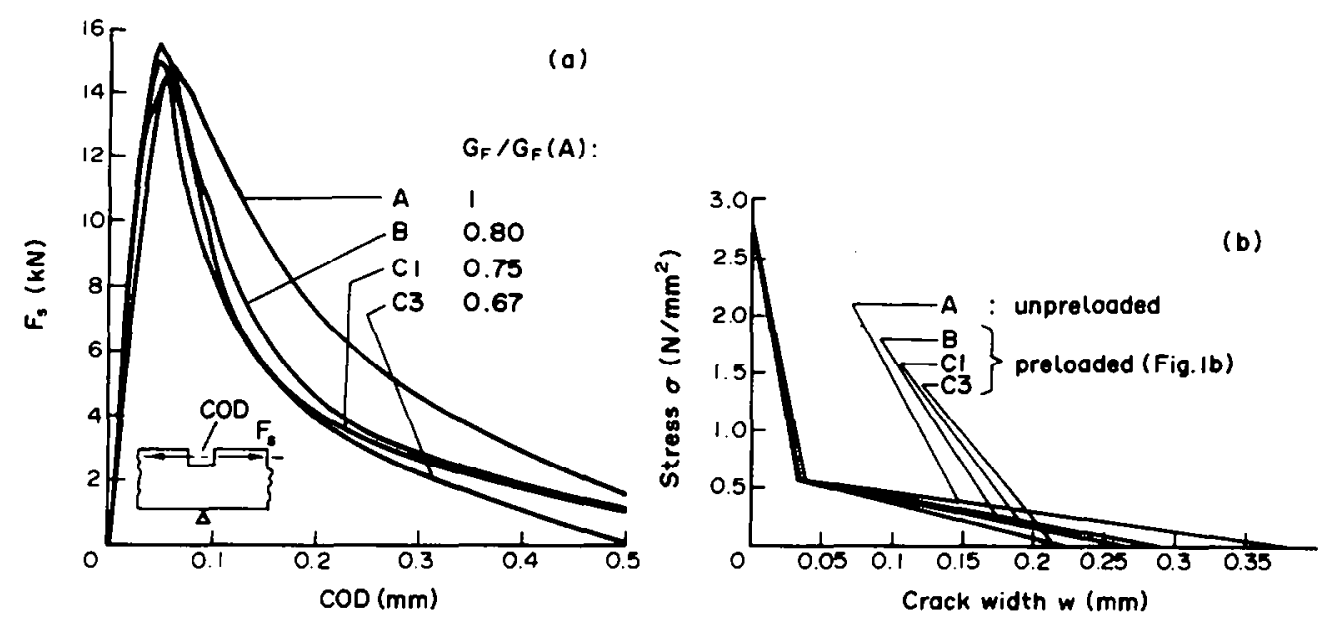

Fig. 5. Effect of compressive preloading on $G_{\mathrm{F}}$ and strain softening at quasi-static COD-rate. (a) Splitting force-crack opening displacement-mean curves. (b) Bilinear strain-softening diagrams.

- The relationship between mechanical properties and deformation rate can often be described by a power law; i.e. on a doubly-logarithmic scale, strength increases linearly with rate. As a consequence, an exact knowledge of the rate of deformation is not always necessary.

On the basis of these general findings a procedure for the development of material laws is proposed:

- The tensile behaviour of concrete is subdivided into the stage preceding the reaching of tensile strength and a post-peak stage with strain softening.

- A normalized material law is introduced, where stresses and deformations are related to a characteristic value such as the tensile strength, failure strain, maximum crack width or the ratio $G_{\mathrm{F}} / f_{\mathrm{i}}$ (Fig. 5).

- The absolute material law used for the analysis is obtained by a transformation which is based on the knowledge of the quasi-static properties $S_{0}$ of unpreloaded concrete.

-Simple relations for the absolute material properties $S$ as a function of the seismic "loading history" (i.e. deformation rate $\dot{v}$ and preloading $D$ ) are proposed in[2]; they can he generalized as follows:

The effect of deformation rate on mechanical properties is expressed by a power law:

$$
S=S_{0}(\dot{v})^{\mathrm{p}}
$$

where $v$ is the (constant) deformation rate and $\mathrm{p}$ is an exponent determined from test results. The effect of compressive proloading on mechanical properties is quantified according to damage mechanics, e.g.

$$
S=S_{0}\left(1-D_{\mathrm{s}}\right)
$$
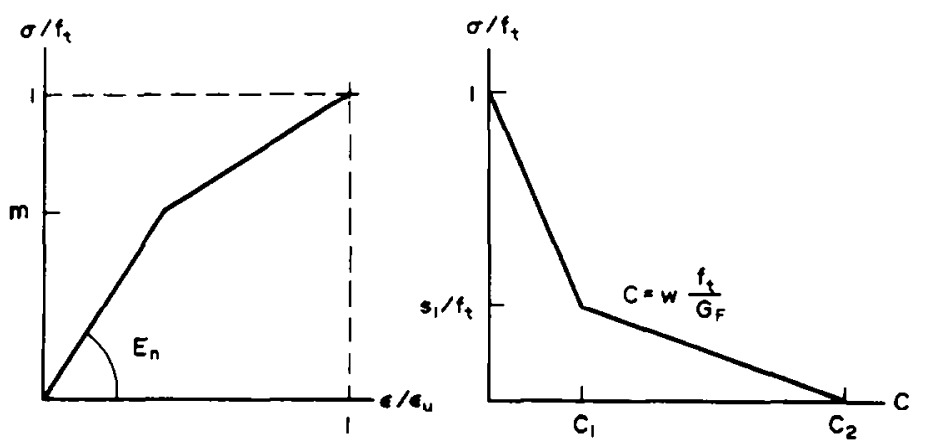

Fig. 6. Schematic presentation of a normalized material law for concrete in tension. 
with $D_{\mathrm{s}}$ as a damage scalar $\left(0<D_{\mathrm{s}}<1\right)$ describing the material damage due to compressive preloading.

-In view of a general applicability, aspects such as multiaxial dynamic loading and variation of deformation rates as well as the effect of unloading/reloading cycles must be considered.

A constitutive relation for plane stress problems with particular regard to the effects of strain rate, progressive damage and strain softening in discrete cracks has recently been proposed for structures like dams[7].

\section{CONCLUSIONS}

- The most important difference in the fracture mechanics properties of normal and dam concrete lies in the specific fracture energy $G_{\mathrm{F}} . G_{\mathrm{F}}$ of dam concrete can be several times greater than $G_{\mathrm{F}}$ of common concrete. This finding is explained rather by the nature and the fracture properties of aggregates than by the larger maximum aggregate grain size of dam concrete.

- No important fracture mechanics property is reduced at high loading rates. The tensile strength and the specific fracture energy show a high rate sensitivity. The rate effect on the $G_{\mathrm{F}}$-value can be attributed to the rate sensitivity of the tensile strength.

-Dynamic compressive preloading leads to a reduction of fracture mechanics properties. Especially the specific fracture energy $G_{\mathrm{F}}$ of preloaded dam concrete decreases considerably with increasing "intensity" of the preloading.

-The stress-strain diagram under tensile loading can be subdivided into two portions: an ascending branch with little non-linearity, and a descending branch with pronounced strain softening. Diagrams normalized with respect to the quasi-static properties of unpreloaded concrete clearly reveal the effect of, e.g. strain rate and compressive preloading. This normalized representation can serve for the elaboration of material laws.

Acknowledgement - This research was supported by the Swiss Federal Office for Dam Safety under the direction of Dr R. Biedermann.

\section{REFERENCES}

[1] S. Mindess and S. P. Shah (Eds), Cement-based composites: strain rate effects of fracture. MRS Symposia-Proc., 64, Materials Research Society, Pittsburgh (1986).

[2] E. Brühwiler, Fracture machanics of dam concrete subjected to quasi-static and seismic loading conditions. Doctoral Thesis, Laboratory for Building Materials, Swiss Federal Institutue of Technology Lausanne, (1988) (in German with an extended summary in English).

[3] E. Brühwiler and F. H. Wittmann, The wedge splitting test, a method of performing stable fracture mechanics tests. Engn Fracture Mech. 35, 117-125 (1990).

[4] P. E. Roelfstra and F. H. Wittmann, Numerical methods to link strain softening with failure of concrete, in Fracture Toughness and Fracture Energy (Edited by F. H. Wittmann), pp. 163-175. Elsevier, Amsterdam (1986).

[5] E. Brühwiler, Experiments on the influence of compressive preloading on the behaviour of dam concrete in tension at high strain rates. Test Report, Laboratory for Building Materials, Swiss Federal Institute of Technology, Lausanne (1987) (in German).

[6] H. Mihashi and F. H. Wittmann, Stochastic approach to study the influence of rate of loading on strength of concrete. HERON (The Netherlands) 25 (1980).

[7] $\mathrm{Ph}$. Chappuis, Nonlinear modelling of the material behaviour of concrete subjected to dynamic loading. Doctoral Thesis, Swiss Federal Institute of Technology Zurich, IBK-Report No. 155, Birkhäuser Basel- Boston-Stuttgaert (1987) (in French). 